\title{
Euglenophyta de lagoas da região da Nhecolândia, Pantanal Sul-Matogrossense, Brasil ${ }^{1}$
}

\author{
Deborah Christiane Leite Kufner ${ }^{2,3}$ e Alessandra Giani ${ }^{2}$
}

Recebido: 19.4.2017; aceito: 25.04.2017

\begin{abstract}
Euglenophyta from lakes of Nhecolândia region, Southern Pantanal, Brazil). This study describes and illustrates 50 taxa of the phylum Euglenophyta sampled in four lakes from the Nhecolândia subregion of the Brazilian Pantanal. Of the total taxa identified, 33 were at infra-specific level, with 15 typical varieties and 18 non-typical varieties. Among identified species, Trachelomonas globularis (Awer.) Lemm. var. gigas Drezepolski was recorded for the first time in Brazil, and Lepocinclis americana Conf. and Trachelomonas pyramidata Couté et Thérézien were mentioned for the second time in Brazil. The most abundant genus was Trachelomonas, followed by Lepocinclis and Phacus. The most widespread taxa were Euglena caudata Hübner var. caudata, Lepocinclis acus (Müller) Marin \& Melkonian, L. spyrogiroides Marin \& Melkonian, T. armata (Ehr.) Stein. var. steinii Lemm., T. megalacantha Cunha var. crenulatocollis Bourr. \& Manguin, $T$. superba $\mathrm{Sw}$. var. superba and $T$. volvocinopsis Sw. var. volvocinopsis.
\end{abstract}

Keywords: phytoplankton, floodplain, Pantanal, taxonomy

RESUMO - (Euglenophyta de lagoas da região da Nhecolândia, Pantanal Sul-Matogrossense, Brasil). Este trabalho descreve e ilustra 50 táxons do filo Euglenophyta amostrados em quatro lagoas da sub-região da Nhecolândia, no Pantanal Sul-Matogrossense. Do total de táxons identificados, 33 foram em nível infra-específico, com 15 variedades típicas e 18 variedades não-típicas. Dentre as espécies identificadas, uma nova espécie, Trachelomonas globularis (Awer.) Lemm. var. gigas Drezepolski, foi registrada pela primeira vez no Brasil e duas espécies citadas pela segunda vez: Lepocinclis americana Conforti e Trachelomonas pyramidata Couté et Thérézien. O gênero com maior número de espécies foi Trachelomonas, seguido de Lepocinclis e Phacus. Os táxons com maior distribuição ecológica foram Euglena caudata Hübner var. caudata, Lepocinclis acus (O.F. Müller) Marin \& Melkonian, L. spyrogiroides Marin \& Melkonian, T. armata (Ehr.) Stein. var. steinii Lemm.,T. megalacantha Cunha var. crenulatocollis Bourr. \& Manguin, T. superba Sw. var. superba e T. volvocinopsis Sw. var. volvocinopsis.

Palavras-chave: Fitoplâncton, Pantanal, planície de inundação, taxonomia

\section{Introdução}

A sub-região da Nhecolândia, situada no município de Corumbá, faz parte do cone aluvial do rio Taquari e compreende um sistema lacustre rico em corpos d'água subcirculares, que podem se conectar periodicamente aos rios Taquari e Negro (Allem \& Valls 1987, Abdon et al. 1998). As lagoas que compõem a sub-região podem ser de água doce, conhecidas regionalmente por "baías", e de água alcalina, chamadas "salinas".

O pulso de inundação que ocorre periodicamente na região provoca efeito de diluição de nutrientes das lagoas e é caracterizado como o principal fator que influencia a estrutura e a dinâmica das comunidades aquáticas (Neiff 1990). O regime hidrológico local é complexo e as conexões de águas subterrâneas ligando as várias lagoas da região ainda não são conhecidas.

Apesar dos numerosos lagos que compõem a planície pantaneira, existem ainda relativamente poucos trabalhos sobre a comunidade fitoplanctônica para o Pantanal Sul, sendo que a maioria dos estudos aborda aspectos estruturais e a influência do pulso de inundação em rios, baías e salinas (Espíndola et al. 1996, Oliveira \& Calheiros 2000, Domitrovic 2002, Cardoso et al. 2012, Malone et al. 2012) e apenas

1 Parte da Tese de Doutorado da primeira Autora

2. Universidade Federal de Minas Gerais, Programa de Pós-Graduação em Biologia Vegetal, Av. Presidente Antônio Carlos, 6.627, Pampulha, 31270-901 Belo Horizonte, MG, Brasil

3. Autor para correspondência: deborah.clk@gmail.com 
um aborda a taxonomia do fitoplâncton (Santos \& Sant'Anna 2010).

As Euglenophyta pigmentadas correspondem a um importante grupo de algas unicelulares (exceto gênero Colacium, que são coloniais) do fitoplâncton de água doce, são livre-natantes devido à presença de flagelo e estão presentes no mundo todo, especialmente em ambientes rasos, ricos em matéria orgânica, fósforo e nitrogênio (Round 1983, Wetzel 2001, Alves-da-Silva et al. 2013), além de serem importantes sinalizadoras de ambientes poluídos (Palmer 1969).

Este trabalho apresenta o levantamento taxonômico das Euglenophyta presentes em lagoas rasas da sub-região da Nhecolândia e inclui a distribuição geográfica no Brasil, além de descrição e ilustração de cada táxon com a finalidade de ampliar o conhecimento taxonômico desse grupo para o Pantanal.

\section{Material e métodos}

A amostragem do fitoplâncton foi realizada em janeiro e fevereiro de 2011, em quatro lagoas localizadas em quatro fazendas na sub-região da Nhecolândia, sendo elas: Fazenda Iguaçuzinho $\left(19^{\circ} 09^{\prime} 14^{\prime \prime}\right.$ S e 56 $\left.21^{\circ} 22^{\prime \prime} \mathrm{W}\right)$, fazenda Santa Filomena ( $19^{\circ} 05^{\prime} 45^{\prime \prime S}$ e $\left.56^{\circ} 44^{\prime} 02^{\prime \prime} \mathrm{W}\right)$, fazenda Cáceres $\left(19^{\circ} 07^{\prime} 18^{\prime \prime S}\right.$ e $\left.56^{\circ} 49^{\prime} 04^{\prime \prime} \mathrm{W}\right)$ e fazenda Alegria $\left(19^{\circ} 08^{\prime} 03^{\prime \prime S}\right.$ e $\left.56^{\circ} 48^{\prime} 27^{\prime \prime} \mathrm{W}\right)$. As coletas foram feitas a partir de arrasto horizontal na região central de cada lagoa com rede de plâncton com abertura de malha de $20 \mu \mathrm{m}$. As amostras foram separadas em duas partes: metade foi fixada, ainda no campo, com solução de Transeau e a outra parte foi mantida refrigerada, para observação de material vivo. As amostras foram observadas em microscópio óptico Olympus BX40 e os desenhos foram feitos em câmara clara, acoplada ao microscópio. As amostras foram depositadas no Herbário do Departamento de Botânica da Universidade Federal de Minas Gerais (BHCB154605, BHCB154606, BHCB154607 e BHCB154608).

A condutividade elétrica, o $\mathrm{pH}$, a salinidade e a temperatura da água foram determinadas com uma sonda multiparâmetros YSI 63 e o oxigênio dissolvido com a sonda YSI 55. A matéria orgânica em suspensão foi aferida através do método gravimétrico de acordo com APHA (1998) e a transparência da coluna d'água foi medida com disco de Secchi.

A identificação taxonômica foi feita baseada em populações e foram realizadas medidas de, no mínimo, 20 indivíduos. As medidas de comprimento e largura obtidas foram em seguida utilizadas para o cálculo da relação comprimento e largura de cada indivíduo (Rc/l). Os valores finais correspondem aos valores médios para cada espécie. Neste trabalho foi apresentada também a distribuição geográfica por regiões do Brasil de todos os táxons identificados.

As identificações, descrições e distribuição geográfica foram baseadas em: Deflandre (1926), Pochmann (1942), Conrad \& Van Mell (1952), Tell \& Conforti (1986), Conforti (1993a, b 1994), Alves-daSilva \& Hahn $(2001,2004)$, Alves-da-Silva \& Bridi (2004a, b), Salazar (2004), Zaburlín et al.(2004), Alves-da-Silva \& Fortuna (2006, 2008), Alves-daSilva \& Tamanaha (2008), Tell \& Couté (2008).

\section{Resultados e Discussão}

No levantamento florístico das Euglenophyta de baías do Pantanal da Nhecolândia registrou-se a ocorrência de 50 táxons (tabela 1), distribuídos em seis gêneros, Euglena, Lepocinclis, Monomorphina, Phacus, Strombomonas e Trachelomonas. De todos os táxons identificados, 33 foram em nível infraespecífico, sendo 15 variedades típicas e 18 variedades que não as típicas. $\mathrm{O}$ gênero mais rico em espécies foi Trachelomonas, 24 espécies, seguido de Lepocinclis (10) e Phacus (oito).

\section{Divisão Euglenophyta \\ Classe Euglenophyceae \\ Ordem Euglenales \\ Família Euglenaceae}

Euglena Ehrenberg 1830.

Euglena caudata Hübner var. caudata, (= Euglenaria caudata (Hübner) Karnkowska \& Linton emend. Karnkowska-Ishikawa \& Zakryś). Progr. Realg. Stralsund, p.13. 1886.

\section{Figura 1}

Célula fusiforme, 85-105 $\mu \mathrm{m}$ compr., 36-50 $\mu \mathrm{m}$ larg., $\mathrm{Rc} / 1=3,4-3,5$; polo anterior truncado; processo caudal cônico, ca. 7,5 $\mu \mathrm{m}$ compr.; periplasto com estrias helicoidais; numerosos cloroplastos discoides; pirenoides duplos; numerosos grãos de paramido.

Material examinado: BRASIL. MATo Grosso do SUL: Pantanal da Nhecolândia, fazendas Iguaçuzinho, 2-II-2011, D.C.L. Kufner (BHCB154605), Santa Filomena, 2-II-2011, D.C.L. Kufner (BHCB154606) e Cáceres, 2-II-2011, D.C.L. Kufner (BHCB154607).

Distribuição geográfica no Brasil: Centro-Oeste, Nordeste, Norte, Sudeste e Sul. 
Tabela 1. Ocorrência dos táxons de Euglenophyta registrados em janeiro e fevereiro de 2011 nas lagoas das fazendas Iguaçuzinho, Santa Filomena, Cáceres e Alegria (região de Nhecolândia, Pantanal Sul Matogrossense, Brasil).

Table 1. Occurrence of Euglenophyta taxa recorded in January and February 2011 in lakes of the Iguaçuzinho, Santa Filomena, Cáceres and Alegria farms (Nhecolândia region, Pantanal of Mato Grosso do Sul, Brazil).

\begin{tabular}{lr}
\hline Táxons identificados & Iguaçużn \\
\hline Euglena caudata var. caudata & $\mathrm{X}$ \\
E. splendens var. splendens & $\mathrm{X}$ \\
Lepocinclis acus & \\
L. americana & $\mathrm{X}$ \\
L. fusiformis var. fusiformis & \\
L. ovum var. dimidio-minor & \\
L. oxyuris & \\
L. playfairiana var. striata & \\
L. salina var. salina & \\
L. spirogyroides & \\
L. tripteris & \\
L. truncata var. truncata, &
\end{tabular}

Monomorphina pyrum

Phacus contortus var. contortus

P. curvicauda var. curvicauda

$\mathrm{X}$

$\mathrm{X}$

$\begin{array}{lcc}\text { çuzinho } & \text { Santa Filomena } & \text { Các } \\ \mathrm{X} & \mathrm{X} \\ \mathrm{X} & \\ \mathrm{X} & \\ & \end{array}$

Cáceres

Alegria

$\mathrm{X}$

\section{$\mathrm{X}$}

$\mathrm{X}$

X

P. horridus

$\begin{array}{lll} & & \\ & X & \\ & X & \\ & X & \\ X & X & X \\ X & X & X \\ & X & \\ & X & \\ & X & \\ & X & \\ & X & \\ & X & \\ & X & \end{array}$

P. longicauda var. longicauda

X

P. onyx var. simetrica

P. orbicularis var. orbicularis

$\begin{array}{ll}X & X \\ X & X\end{array}$

P. raciborskii var. longus

X

P. undulatus

$\mathrm{X}$

$\mathrm{X}$

Strombomonas ensifera

$\mathrm{X}$

S. fluviatilis var. levis

$\mathrm{X}$

S. gibberosa var. longicollis

$\mathrm{X}$

S. maxima

$\mathrm{X}$

S. rotunda var. rotunda

$\mathrm{X}$

T. abrupta var. obesa

$\mathrm{X}$

T. acanthophora var. acanthophora

$\mathrm{X}$

T. armata var. steinii

$\mathrm{X}$

X

$\mathrm{X}$

T. bacillifera var. minima

$\mathrm{X}$

$\mathrm{X}$

T. dastuguei

$\mathrm{X}$

T. globularis var. gigas

$\mathrm{X}$

T. hispida var. acuminata

T. hispida var. crenulatocollis

$\mathrm{X}$

T. lemmermannii var. acuminata

$\mathrm{X}$

T. magdaleniana

T. megalacantha var. crenulatocollis

X

X

$\mathrm{X}$

T. molesta

T. naviculiformis

$\mathrm{X}$ 
Tabela 1 (continuação)

\begin{tabular}{|c|c|c|c|c|}
\hline Táxons identificados & Iguaçuzinho & Santa Filomena & Cáceres & Alegria \\
\hline T. pulcherrima var. minor & & & & $\mathrm{X}$ \\
\hline T. pyramidata & & & $\mathrm{X}$ & \\
\hline T. rugulosa & & & $\mathrm{X}$ & \\
\hline T. scabra var. intermedia & & & $\mathrm{X}$ & \\
\hline T. sculpta & & & $\mathrm{X}$ & \\
\hline T. similis var. similis & $\mathrm{X}$ & & & $\mathrm{X}$ \\
\hline T. similis var. spinosa & & & $\mathrm{X}$ & \\
\hline T. superba var. superba & & $\mathrm{X}$ & $\mathrm{X}$ & \\
\hline T. varians var. varians & & & $\mathrm{X}$ & \\
\hline T. volvocina var. derephora & & & $\mathrm{X}$ & \\
\hline T. volvocinopsis var. volvocinopsis & & $\mathrm{X}$ & $\mathrm{X}$ & $\mathrm{X}$ \\
\hline
\end{tabular}

Euglena splendens Dang. var. splendens, Le Botaniste, 8: 69, fig. 9. 1901.

Figura 2

Célula fusiforme, 74-78 $\mu \mathrm{m}$ compr., 36-40 $\mu \mathrm{m}$ larg., $\mathrm{Rc} / \mathrm{l}=2$; processo caudal atenuado bruscamente, hialino e curto; cloroplastos em forma de placas bastante côncavas, com incisões radiais formando bandas em forma de fitas que se estendem até à superfície da célula e se arranjam em espiral, pequeno duplopirenoide; grãos de paramido alongados ou elípticos.

Material examinado: BRASIL. Mato Grosso do SuL: Pantanal da Nhecolândia, fazendas Iguaçuzinho, 2-II-2011, D.C.L. Kufner (BHCB154605) e Cáceres, 2-II-2011, D.C.L. Kufner (BHCB154607).

Distribuição geográfica no Brasil: Sudeste e Sul.

Muito embora a descrição da espécie apresente mucocistos espiralados na membrana, essa característica não foi visualizada para os indivíduos observados, assim como descrito por Swirenko (1915). Primeiro registro para o Pantanal.

Lepocinclis Perty 1852.

Lepocinclis acus (O.F. Müller) Marin \& Melkonian in Marin, Palm, Klingberg, \& Melkonian, Protist 154: 104. 2003.

Figura 3

Célula fusiforme, 92-140 $\mu \mathrm{m}$ compr., 12-19 $\mu \mathrm{m}$ larg., Rc/1 = 7,6-10; polo anterior estreito e truncado; polo posterior atenuado gradativamente em processo caudal cônico, hialino, 10-27 $\mu \mathrm{m}$ compr.; periplasto rígido com estrias longitudinais tênues e de difícil visualização; cloroplastos numerosos, discoides ou alongados, parietais, 1-2 $\mu \mathrm{m}$ diâm.; núcleo central; 2 a 10 grãos de paramido bastoniformes, 11-16 $\mu \mathrm{m}$ compr., 2-3,5 $\mu \mathrm{m}$ larg.

Material examinado: BRASIL. MATo Grosso do SUL: Pantanal da Nhecolândia, fazendas Iguaçuzinho, 2-II-2011, D.C.L. Kufner (BHCB154605), Cáceres, 2-II-2011, D.C.L. Kufner (BHCB154607) e Alegria, 2-II-2011, D.C.L. Kufner (BHCB154608).

Distribuição geográfica no Brasil: Centro-Oeste, Nordeste, Norte, Sudeste e Sul (citado como Euglena acus).

Em estudo filogenético da classe Euglenophyta, Marin et al. (2003) transferiram para Lepocinclis as espécies de Euglena cuja periplasto é rígido, possuem grãos de paramido grandes e ausência de pirenoide.

Lepocinclis americana Conforti, Rev. Hydrobiol. trop. 27(1): 3-21. 1994.

Figura 4

Célula ovada, 53-58 $\mu$ m compr., 25-29 $\mu$ m larg., $\mathrm{Rc} / 1=2-2,1$; polo anterior arredondado; polo posterior terminando gradativamente em processo caudal cônico e hialino; periplasto com estrias ornamentadas por protuberâncias quadradas; dois grandes anéis laterais de paramido; numerosos cloroplastos discoides.

Material examinado: BRASIL. MAto Grosso do SUL: Pantanal da Nhecolândia, fazenda Cáceres, 2-II-2011, D.C.L. Kufner (BHCB154607).

Distribuição geográfica no Brasil: Amazonas.

Primeiro registro para o Pantanal e segundo para o Brasil. 

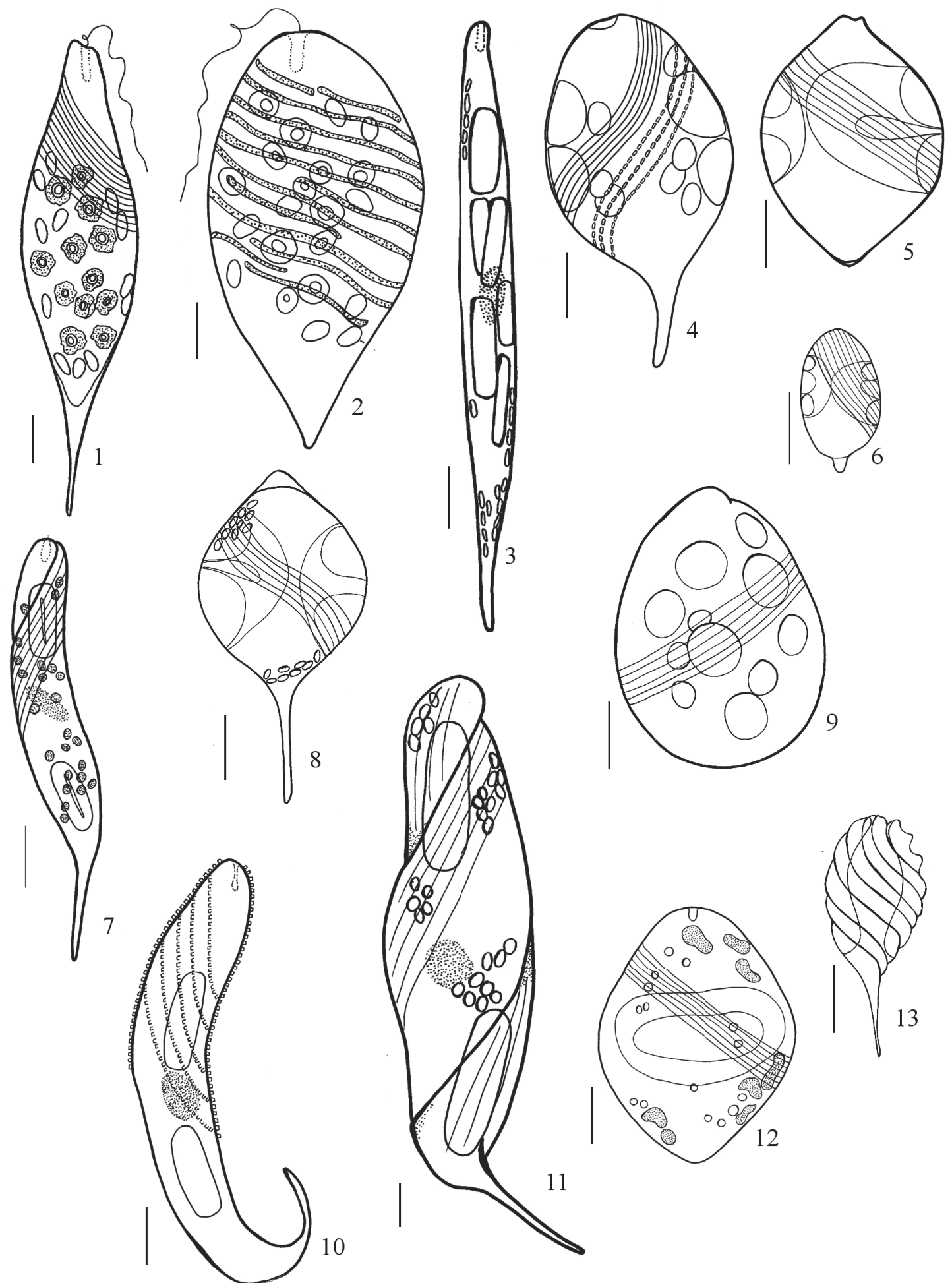

10

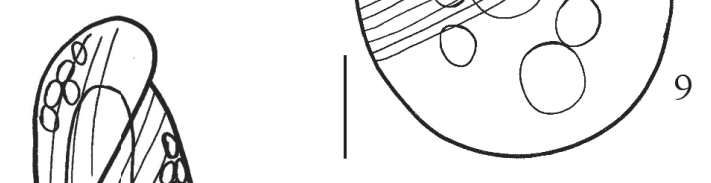

Figuras 1-13. Euglenophyta de lagoas da região da Nhecolândia, Pantanal Sul-Matogrossense, Brasil. 1. Euglena caudata var. caudata. 2. Euglena splendens var. splendens. 3. Lepocinclis acus. 4. Lepocinclis americana. 5. Lepocinclis fusiformis var. fusiformis. 6. Lepocinclis ovum var. dimidio-minor. 7. Lepocinclis oxyuris. 8. Lepocinclis playfairiana var. striata. 9. Lepocinclis salina var. salina. 10. Lepocinclis spirogyroides. 11. Lepocinclis tripteris. 12. Lepocinclis truncata var. truncata. 13. Monomorphina pyrum. Escala $=10 \mu \mathrm{m}$.

Figures 1-13. Euglenophyta from lakes of Nhecolândia region, Southern Pantanal, Brazil. 1. Euglena caudata var. caudata. 2. Euglena splendens var. splendens. 3. Lepocinclis acus. 4. Lepocinclis americana. 5. Lepocinclis fusiformis var. fusiformis. 6. Lepocinclis ovum var. dimidio-minor. 7. Lepocinclis oxyuris. 8. Lepocinclis playfairiana var. striata. 9. Lepocinclis salina var. salina. 10. Lepocinclis spirogyroides. 11. Lepocinclis tripteris. 12. Lepocinclis truncata var. truncata. 13. Monomorphina pyrum. Scale $=10 \mu \mathrm{m}$. 
Lepocinclis fusiformis (Carter) Lemm. emend. Conr. var. fusiformis, Arch. Protistenk., 82(2):255. fig. 30. 1934.

Figura 5

Célula citriforme ou amplamente fusiforme, 30-35 $\mu \mathrm{m}$ compr., 21-26 $\mu \mathrm{m}$ larg., $\mathrm{Rc} / 1=1,3-1,4$; polo posterior levemente atenuado; periplasto com estrias levógiras; dois grãos de paramido em formato de anel.

Material examinado: BRASIL. Mato Grosso do Sul: Pantanal da Nhecolândia, fazendas Iguaçuzinho, 2-II-2011, D.C.L. Kufner (BHCB154605) e Cáceres, 2-II-2011, D.C.L. Kufner (BHCB154607).

Distribuição geográfica no Brasil: Centro-Oeste, Norte, Sudeste e Sul.

Lepocinclis ovum (Ehr.) Lemm. var. dimidio-minor Defl., Bull. Soc. Bot. Fr., 24(4):1121.fig. 25-28. 1924. Figura 6

Célula elíptica a oblonga-elíptica, 18-20 $\mu \mathrm{m}$ compr., 11-13,5 $\mu \mathrm{m}$ larg., Rc/1 = 1,5; polo anterior arredondado; polo posterior mamilado; periplasto rígido, com estrias levógiras; numerosos cloroplastos parietais discoides, ca. 3,6 $\mu \mathrm{m}$ diâm.

Difere da espécie tipo pelo tamanho menor.

Material examinado: BRASIL. MATo Grosso do SuL: Pantanal da Nhecolândia, fazenda Cáceres, 2-II-2011, D.C.L. Kufner (BHCB154607).

Distribuição geográfica no Brasil: Centro-Oeste, Norte, Sudeste e Sul.

Lepocinclis oxyuris (Schm.) Marin et Melkonian, Palm, Klingberg \& Melkonian, Protist 154: 104. 2003.

Figura 7

Célula cilíndrica, 67-79 $\mu \mathrm{m}$ compr., 8-14 $\mu \mathrm{m}$ larg., $\mathrm{Rc} / 1=5,6-8,3$; abertura do canal subapical; polo anterior arredondado ou truncado, polo posterior atenuado em processo caudal cônico, hialino, 12-18 $\mu \mathrm{m}$ compr.; estrias helicoidais, acompanhando a torção do corpo; numerosos cloroplastos discoides, parietais, 2-3,5 $\mu \mathrm{m}$ diâm.; dois grãos de paramido bastoniformes, centrais, um anterior e outro posterior ao núcleo central.

Material examinado: BRASIL. MATo Grosso do SuL: Pantanal da Nhecolândia, fazendas Santa Filomena, 2-II-2011, D.C.L. Kufner (BHCB154606) e Cáceres, 2-II-2011, D.C.L. Kufner (BHCB 54607).
Distribuição geográfica no Brasil: Centro-Oeste, Nordeste, Norte, Sudeste e Sul (citada como Euglena oxyuris, com exceção no Nordeste que foi citado como L. oxyuris).

Lepocinclis playfairiana Defl. var. striata, Ann. de Protist., 2:16. fig. 23. 1929.

Figura 8

Célula amplamente ovada, 45-58 $\mu \mathrm{m}$ compr., 31-37 $\mu \mathrm{m}$ larg., $\mathrm{Rc} / 1=1,4-1,5$; polo anterior levemente pronunciado e assimétrico; polo posterior atenuado em processo caudal reto, 7-8 $\mu$ m compr.; estrias levógiras; 1-2 grãos de paramido anelares e opostos; numerosos cloroplastos discoides, ca. $1 \mu \mathrm{m}$ diâm.

Material examinado: BRASIL. Mato Grosso do Sul: Pantanal da Nhecolândia, fazenda Cáceres, 2-II-2011, D.C.L. Kufner (BHCB154607).

Distribuição geográfica no Brasil: Norte e Sul.

Lepocinclis salina Fritsch var. salina, New Phytologist. 13:351. fig. 3a-b, e. 1914.

Figura 9

Célula ovada, 39-44 $\mu$ m compr., 20-23 $\mu$ m larg., $\mathrm{Rc} / 1=1,9$; polos arredondados; estrias dextrogiras; numerosos grãos de paramido discoides, 7-9 $\mu \mathrm{m}$ diâm.

Material examinado: BRASIL. MAto GRosso do Sul: Pantanal da Nhecolândia, fazendas Cáceres, 2-II-2011, D.C.L. Kufner (BHCB154607) e Alegria, 2-II-2011, D.C.L. Kufner (BHCB154608).

Distribuição geográfica no Brasil: Centro-Oeste, Norte, Sudeste e Sul.

Lepocinclis spirogyroides Marin \& Melkonian, Marin, Palm, Klingberg \& Melkonian, Protist 154:104. 2003.

Figura 10

Célula fusiforme, $88-138 \mu \mathrm{m}$ compr. 11-27 $\mu \mathrm{m}$ larg., Rc/1 = 5,1-8; polo anterior truncado; polo posterior atenuado em processo caudal cônico levemente curvado, 17,5-25,0 $\mu \mathrm{m}$ compr.; periplasto espiralado, estrias poligonais; numerosos cloroplastos, discoides; dois grãos de paramido bastoniformes.

Material examinado: BRASIL. MATo GRosso do SuL: Pantanal da Nhecolândia, fazendas Santa Filomena, 2-II-2011, D.C.L. Kufner (BHCB154606), Cáceres, 2-II-2011, D.C.L. Kufner (BHCB154607) e Alegria, 2-II-2011, D.C.L. Kufner (BHCB154608). 
Distribuição geográfica no Brasil: Centro-Oeste, Nordeste, Sul e Sudeste (citados como Euglena oxyuris, sendo apenas na região Nordeste citado como Lepocinclis oxyuris).

Lepocinclis tripteris (Duj.) Marin \& Melkonian in Marin, Palm, Klingberg \& Melkonian, Protist 154: 104. 2003.

Figura 11

Célula fusiforme, 91-144 $\mu \mathrm{m}$ compr., 30-36 $\mu \mathrm{m}$ larg., Rc/1 = 3-4; às vezes torcida duas vezes; polo anterior truncado; polo posterior terminado em processo caudal cônico, hialino, levemente inclinado, 29-34 $\mu \mathrm{m}$ compr.; estrias longitudinais acompanhando a torção do corpo; dois grãos de paramido bastoniformes, ca. $30 \mu \mathrm{m}$ compr., ca. $15 \mu \mathrm{m}$ larg., um localizado anterior e outro posterior ao núcleo; cloroplastos numerosos, discoides, 2-3 $\mu \mathrm{m}$ diâm.

Material examinado: BRASIL. MAto GRosso do SuL: Pantanal da Nhecolândia, fazendas Santa Filomena, 2-II-2011, D.C.L. Kufner (BHCB154606) e Cáceres, 2-II-2011, D.C.L. Kufner (BHCB154607).

Distribuição geográfica no Brasil: Norte, Sudeste e Sul (citado como Euglena tripteris).

Lepocinclis truncata Cunha var. truncata, Memórias do Instituto Oswaldo Cruz. 6 (3):170, pl. 24. fig. 1. 1914.

Figura 12

Célula romboide, $42-50 \mu \mathrm{m}$ compr., $30-37 \mu \mathrm{m}$ larg., $\mathrm{Rc} / 1=1,3-1,4$; polo anterior truncado, polo posterior arredondado; periplasto com estrias levógiras; cloroplastos numerosos; 1-2 grãos de paramido em forma de anel, parietais.

Material examinado: BRASIL. Mato Grosso do Sul: Pantanal da Nhecolândia, fazenda Cáceres, 2-II-2011, D.C.L. Kufner (BHCB154607).

Distribuição geográfica no Brasil: Centro-Oeste e Sul.

Monomorphina Mereschkowsky 1877.

Monomorphina pyrum (Ehr.) Mereschkovsky emend Kosmala \& Zakrys, J. Phycol. 43:177, 179, fig. 1-11, 13-15, 17. 2007.

Figura 13

Célula piriforme, $18,0-36,5 \mu \mathrm{m}$ compr., 6,5-15,0 $\mu \mathrm{m}$ larg., $\mathrm{Rc} / 1=2,4-2,7$; polo anterior arredondado; polo posterior terminado em processo caudal cônico, reto, hialino, 6-8,5 $\mu \mathrm{m}$ compr.; em média sete quilhas hialinas levógiras.

Material examinado: BRASIL. Mato Grosso do SuL: Pantanal da Nhecolândia, fazenda Cáceres, 2-II-2011, D.C.L. Kufner (BHCB154607).

Distribuição geográfica no Brasil: Centro-Oeste, Norte, Sudeste e Sul.

Phacus Dujardin 1841.

Phacus contortus Bourr. var. contortus, Bourrelly \& Manguin, Algues d'eau dou ce Guad. Dep., 177, pl. 22, fig. 271-272. 1952.

Figura 14

Célula assimétrica, $42-45 \mu \mathrm{m}$ compr., 30-32 $\mu \mathrm{m}$ larg., Rc/1=1,3-1,4; ovada; polo anterior arredondado, abertura do canal subapical; polo posterior atenuado abruptamente em processo caudal cônico, hialino, curvo, 11,5-13,0 $\mu \mathrm{m}$ compr.; periplasto hialino, estrias longitudinais seguindo a torção celular; margens diferentemente espessadas; vista lateral mais ou menos triangular e torcida; numerosos cloroplastos discoides, ca. $3 \mu \mathrm{m}$ diâm.; dois grãos de paramido discoides dispostos em cada lado da célula, 12-14 $\mu \mathrm{m}$ diâm.

Material examinado: BRASIL. Mato Grosso do Sul: Pantanal da Nhecolândia, fazendas Cáceres, 2-II-2011, D.C.L. Kufner (BHCB154607) e Alegria, 2-II-2011, D.C.L. Kufner (BHCB154608).

Distribuição geográfica no Brasil: Centro-Oeste, Norte, Sudeste, Sul.

Phacus curvicauda Swir. var. curvicauda, Arch., Hydrobiol. Plankton.10: 333, pl. 2, fig. 13-16.1915. Figura 15

Célula amplamente ovada, 30-57 $\mu \mathrm{m}$ compr., 20-43 $\mu \mathrm{m}$ larg., $\mathrm{Rc} / 1=1,3-1,5$; processo caudal geralmente curto, curvado, 5-7 $\mu \mathrm{m}$ de compr.; células torcidas, divididas em duas porções igual ou diferentemente espessadas; polo posterior abruptamente atenuado em processo caudal hialino, curvado, 5-6,5 $\mu \mathrm{m}$ compr.; periplasto hialino, estrias longitudinais seguindo a torção celular; cloroplastos numerosos, discoides, ca. $2 \mu \mathrm{m}$ diâm.; 1-2 grãos de paramido discoides de tamanhos desiguais.

Material examinado: BRASIL. Mato Grosso do Sul: Pantanal da Nhecolândia, fazendas Iguaçuzinho, 2-II-2011, D.C.L. Kufner (BHCB154605), Cáceres, 2-II-2011, D.C.L. Kufner (BHCB154607) e Alegria, 2-II-2011, D.C.L. Kufner (BHCB154608). 

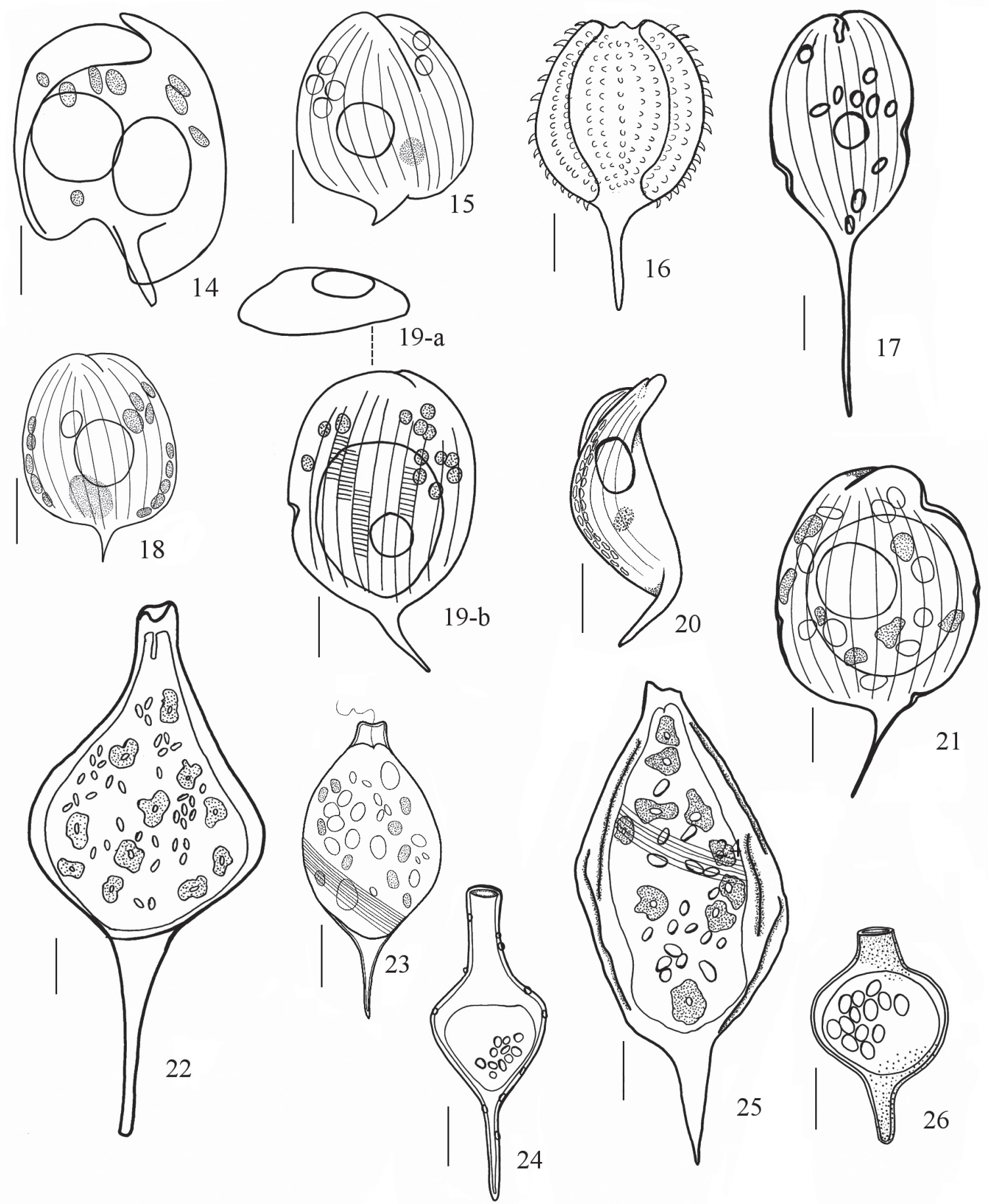

Figuras 14-26. Euglenophyta de lagoas da região da Nhecolândia, Pantanal Sul-Matogrossense, Brasil. 14. Phacus contortus var. contortus. 15. Phacus curvicauda var. curvicauda. 16. Phacus horridus. 17. Phacus longicauda var. longicauda. 18. Phacus onxy var. simetrica. 19a-b. Phacus orbicularis var. orbicularis. 20. Phacus raciborskii var. longus. 21. Phacus undulatus. 22. Strombomonas ensifera. 23. Strombomonas fluviatilis var. levis. 24. Strombomonas gibberosa var. longicollis. 25. Strombomonas maxima. 26. Strombomonas rotunda var. rotunda. Escala $=10 \mu \mathrm{m}$.

Figures 14-26. Euglenophyta from lakes of Nhecolândia region, Southern Pantanal, Brazil. 14. Phacus contortus var. contortus. 15. Phacus curvicauda var. curvicauda. 16. Phacus horridus. 17. Phacus longicauda var. longicauda. 18. Phacus onxy var. simetrica. 19a-b. Phacus orbicularis var. orbicularis. 20. Phacus raciborskii var. longus. 21. Phacus undulatus. 22. Strombomonas ensifera. 23. Strombomonas fluviatilis var. levis. 24. Strombomonas gibberosa var. longicollis. 25. Strombomonas maxima. 26. Strombomonas rotunda var. rotunda. Scale $=10 \mu \mathrm{m}$. 
Distribuição geográfica no Brasil: Centro-Oeste, Nordeste, Norte, Sudeste e Sul.

Phacus horridus Pochm., Arch. Protistenk., 95(2): 239. fig. 163 a- b. 1942.

Figura 16

Célula amplamente ovada, 48-55 $\mu \mathrm{m}$ compr., 26-30 $\mu \mathrm{m}$ larg., $\mathrm{Rc} / 1=1,8$; simétrica; polo anterior com uma papila mediana, obtusa; polo posterior terminado em processo caudal cônico, reto, 12-15 $\mu \mathrm{m}$ compr.; periplasto com estrias longitudinais, ornamentadas com espinhos conspícuos curvados para baixo, ca. $1 \mu \mathrm{m}$ de compr., alternadas com estrias lisas.

Material examinado: BRASIL. Mato Grosso do Sul: Pantanal da Nhecolândia, fazenda Cáceres, 2-II-2011, D.C.L. Kufner (BHCB154607).

Distribuição geográfica no Brasil: Centro-Oeste, Norte e Sul.

Primeiro registro para o Pantanal.

Phacus longicauda (Ehrenberg) Dujardin var. longicauda, Hist. nat. Zoophytes. 337, pl. 5, fig. 6. 1841.

Figura 17

Célula elíptica a ligeiramente obovada, 118-125 $\mu \mathrm{m}$ compr., 40-45 $\mu \mathrm{m}$ larg., Rc/1 = 2,7-2,9; simétrica ou pouco simétrica, não torcida ou torcida apenas no processo caudal; polo anterior arredondado, abertura do canal subapical; polo posterior atenuado em processo caudal longo, 50-53 $\mu \mathrm{m}$ compr., cônico, hialino; periplasto rígido com estrias longitudinais; numerosos cloroplastos discoides a elípticos; paramidos 2, discoides.

Material examinado: BRASIL. MAto Grosso do SuL: Pantanal da Nhecolândia, fazenda Santa Filomena, 2-II-2011, D.C.L. Kufner (BHCB154606).

Distribuição geográfica no Brasil: Norte, Sudeste e Sul.

Os autores Kosmala et al. (2007) apontam que a presença de bordas cortadas ou dentadas relaciona-se com o processo de degradação da célula.

Phacus onyx Pochm. var. simetrica Tell \& Domitrovic, Nova Hedwigia 41: 360, pl. 7, fig. 9a-c. 1985. Figura 18

Célula ovada, arredondada, simétrica, 30-35 $\mu \mathrm{m}$ compr., 19-23 $\mu \mathrm{m}$ larg., $\mathrm{Rc} / 1=1,5$; as margens podem apresentar reentrâncias ou não; processo caudal reto, 8-13 $\mu \mathrm{m}$ compr.; numerosos cloroplastos discoides.

Material examinado: BRASIL. Mato Grosso do Sul: Pantanal da Nhecolândia, fazenda Cáceres, 2-II-2011, D.C.L. Kufner (BHCB154607).

Distribuição geográfica no Brasil: Centro-Oeste e Sul.

Phacus orbicularis Hübner var. orbicularis, Prog. Realgym. Stralsund., p. 5, fig. 41. 1886.

Figuras 19a-b

Célula ovada, 50-60 $\mu \mathrm{m}$ compr., 30-42 $\mu \mathrm{m}$ larg., $\mathrm{Rc} / 1=1,4-1,6$; polo anterior arredondado, vista apical levemente triangular; polo posterior terminado em processo caudal levemente inclinado, cônico; estrias transversais entre as estrias longitudinais; numerosos cloroplastos discoides, dispostos parietalmente, ca. $2 \mu \mathrm{m}$ diâm, 1 ou 2 grãos de paramido.

Material examinado: BRASIL. Mato Grosso do Sul: Pantanal da Nhecolândia, fazendas Santa Filomena, 2-II-2011, D.C.L. Kufner (BHCB154606) e Cáceres, 2-II-2011, D.C.L. Kufner (BHCB154607).

Distribuição geográfica no Brasil: Centro-Oeste, Norte, Sudeste, Sul.

Phacus raciborskii Drez. var. longus Conforti, Cryptogamie, Algol., 10 (1): 73, fig. 3 a-e. 1989. Figura 20

Célula geralmente retangular, dobrada em sela, 34-68 $\mu \mathrm{m}$ compr., 11-20 $\mu \mathrm{m}$ larg., $\mathrm{Rc} / 1=3-3,4$; polo posterior terminado em processo caudal cônico, hialino, curvado, 10-15 $\mu \mathrm{m}$ compr.; estrias longitudinais acompanhando a torção do periplasto; numerosos cloroplastos, discoides, 1-1,5 $\mu \mathrm{m}$ diâm.; 2 grãos de paramido bastoniformes.

Material examinado: BRASIL. Mato Grosso do Sul: Pantanal da Nhecolândia, fazenda Cáceres, 2-II-2011, D.C.L. Kufner (BHCB154607).

Distribuição geográfica no Brasil: Norte e Sul.

Phacus undulatus (Skv.) Pochm., Arch. Protistenk. 95(2): 191, fig. 95-96. 1942.

Figura 21

Célula ovada, 56-63 $\mu \mathrm{m}$ compr., 35-42 $\mu \mathrm{m}$ larg., $\mathrm{Rc} / 1=1,5-1,6$; assimétrica, com entalhes marginais no periplasto; polo anterior arredondado; polo posterior terminado em processo caudal longo, hialino, inclinado, 12-13 $\mu \mathrm{m}$ compr.; estrias longitudinais 
e transversais; numerosos cloroplastos discoides, 5-12 $\mu$ m diâm.; 2 grãos de paramido, um centralizado e outro excêntrico.

Material examinado: BRASIL. Mato Grosso do SuL: Pantanal da Nhecolândia, fazenda Cáceres, 2-II-2011, D.C.L. Kufner (BHCB154607).

Distribuição geográfica: Norte e Sul.

Strombomonas Deflandre 1930.

Strombomonas ensifera (Daday) Defl., Arch. Protistenk. 69 (3): 601. 1930.

Figura 22

Lórica alargada/arredondada na região mediana, 85-119 $\mu$ m compr., 37-48 $\mu$ m larg., Rc/l = 2,3-2,5; polo anterior atenuado em colarinho cilíndrico, truncado, com 7-8 $\mu \mathrm{m}$ diâm.; processo caudal atenuado, geralmente estreito, ca. $30 \mu \mathrm{m}$ de compr.; parede delgada, castanho-clara; numerosos cloroplastos discoides, haplopirenoides presentes , 3,7-4,6 $\mu \mathrm{m}$ diâm.; grãos de paramido arredondados ou alongados.

Material examinado: BRASIL. Mato Grosso do Sul: Pantanal da Nhecolândia, fazenda Cáceres, 2-II-2011, D.C.L. Kufner (BHCB154607).

Distribuição geográfica no Brasil: Centro-Oeste, Nordeste, Norte, Sudeste e Sul.

Strombomonas fluviatilis (Lemm.) Defl. var. levis (Lemm.) Defl., Arch. Protistenkd. 69: 581. fig. 55-56. 1930

Figura 23

Lórica amplamente elíptica, 52-73 $\mu \mathrm{m}$ compr., 25-32 $\mu \mathrm{m}$ larg., Rc/1 = 2,2-2,8; colarinho curto, 4,3-5,5 $\mu \mathrm{m}$ alt. e 6,6-7,8 $\mu \mathrm{m}$ larg.; bordo indistinto, crenulado; polo posterior atenuado em processo caudal cônico, 13-16 $\mu \mathrm{m}$ compr.; célula com estrias levógiras, cloroplastos discoides a ovais 2,7-4,0 $\mu$ m diâm.; grãos de paramido discoides a alongados, 3,4-5,7 $\mu \mathrm{m}$ diâm.

Material examinado: BRASIL. Mato Grosso do SuL: Pantanal da Nhecolândia, fazenda Cáceres, 2-II-2011, D.C.L. Kufner (BHCB154607).

Distribuição geográfica no Brasil: Nordeste e Sul.

Diferencia-se da espécie tipo pelas maiores dimensões.

Strombomonas gibberosa (Playf.) Defl. var. longicollis

(Playf.) Defl., Arch. Protistenk., 69 (3):598., fig. 93-103. 1930.

Figura 24
Lórica amplamente romboide, 53,5-55 $\mu \mathrm{m}$ compr., 19-23 $\mu \mathrm{m}$ larg., Rc/1=2,3-2,8; região mediana mais ou menos angular; lados convexos, afinando rapidamente para o colarinho cilíndrico alto, ca. $15 \mu \mathrm{m}$ de alt., ca. $6 \mu \mathrm{m}$ de larg., bordo liso; processo caudal longo, atenuado, reto ou levemente curvado, ca. $19 \mu \mathrm{m}$ compr.; parede da lórica acastanhada, lisa, com pequenas aglutinações superficiais; numerosos cloroplastos discoides.

Material examinado: BRASIL. Mato Grosso do Sul: Pantanal da Nhecolândia, fazenda Cáceres, 2-II-2011, D.C.L. Kufner (BHCB154607).

Distribuição geográfica no Brasil: Norte e Sul.

Difere da espécie típica pela maior dimensão do colarinho.

Strombomonas maxima (Skvortzov) Defl., Arch. Protistenkd. 69:583. fig. 61-65. 1930.

Figura 25

Lórica ovada, 77-87 $\mu \mathrm{m}$ compr., 32-37 $\mu \mathrm{m}$ larg., $\mathrm{Rc} / \mathrm{l}=$ 2,4; colarinho cilíndrico, 6-8 $\mu \mathrm{m}$ diâm., reto, levemente crenulado; processo caudal cônico; parede lisa, com pregas longitudinais e transversais, marrom-clara; numerosos cloroplastos discoides, haplopirenoides presentes; grãos de paramido arredondados ou alongados.

Material examinado: BRASIL. Mato Grosso do Sul: Pantanal da Nhecolândia, fazenda Cáceres, 2-II-2011, D.C.L. Kufner (BHCB154607).

Distribuição geográfica no Brasil: Centro-Oeste, Norte, Sudeste e Sul.

Strombomonas rotunda (Playfair) Defl. var. rotunda, Arch. Protistenkd. 69 (3):593. fig. 88. 1930

Figura 26

Lórica transversalmente elíptica, 27-32 $\mu \mathrm{m}$ compr., 15-17 $\mu \mathrm{m}$ larg., $\mathrm{Rc} / 1=1,8-2$; mais larga na região mediana; colarinho reto, liso a levemente crenulado; polo posterior com processo caudal cônico; parede da lórica levemente rugosa, acastanhada; cloroplastos e grãos de paramido numerosos.

Material examinado: BRASIL. Mato Grosso do Sul: Pantanal da Nhecolândia, fazenda Cáceres, 2-II-2011, D.C.L. Kufner (BHCB154607).

Distribuição geográfica no Brasil: Nordeste, Norte, Sul e Sudeste. 
Trachelomonas Ehrenberg emend. Deflandre 1926.

Trachelomonas abrupta Swir. emend. Defl. var. obesa (Playf.) Defl. Nemours, p. 93. fig. 353, 362, 363. 1926.

Figura 27

Lórica amplamente elíptica, ca. $25 \mu \mathrm{m}$ compr., 20-22 $\mu \mathrm{m}$ larg., $\mathrm{Rc} / 1=1,1$; polo anterior com espessamento anelar; parede pontuada.

Material examinado: BRASIL. MAto Grosso do SuL: Pantanal da Nhecolândia, fazenda Cáceres, 2-II-2011, D.C.L. Kufner (BHCB154607).

Distribuição geográfica no Brasil: Norte e Sul.

Difere da típica da espécie por ser comparativamente mais larga que as demais variedades.

Trachelomonas acanthophora Stokes var. acanthophora, Proc. Amer. Philos. Soc. 33: 340, pl. 11XXI: fig. 6. 1894.

Figura 28

Lórica elíptica, 48-53 $\mu \mathrm{m}$ compr. 18-22 $\mu \mathrm{m}$ larg., $\mathrm{Rc} / 1=2,5$; polo anterior com colarinho cilíndrico, ca. $5 \mu \mathrm{m}$ compr., terminado com espinhos fortes, em média quatro; polo posterior terminado em processo caudal longo, ca. $7 \mu \mathrm{m}$ compr., cilíndrico, com três espinhos divergentes, ca. $4 \mu \mathrm{m}$ compr.; curvados; lórica ornamentada com espinhos, cônicos, curvados.

Material examinado: BRASIL. Mato Grosso do Sul: Pantanal da Nhecolândia, fazenda Iguaçuzinho, 2-II-2011, D.C.L. Kufner (BHCB154605).

Distribuição Geográfica no Brasil: Nordeste, Norte, Sudeste e Sul.

Trachelomonas armata (Ehr.) Stein. var. steinii Lemm., Rev. Gén. Bot., 38:88. fig. 314-316, 322-324, 326-327. 1926.

Figura 29

Lórica ovada, 40-44 $\mu \mathrm{m}$ compr., 36-39 $\mu \mathrm{m}$ larg., $\mathrm{Rc} / 1=1,1$; polo anterior às vezes estreito e polo posterior com coroa de espinhos fortes, ligeiramente curvados; parede da lórica pontuada, decorada em torno do poro com espinhos de número irregular; cloroplastos discoides.

Material examinado: BRASIL. MAto Grosso do SuL: Pantanal da Nhecolândia, fazendas Iguaçuzinho, 2-II-2011, D.C.L. Kufner (BHCB154605), Santa Filomena, 2-II-2011, D.C.L. Kufner (BHCB154606) e Cáceres, 2-II-2011, D.C.L. Kufner (BHCB154607).
Distribuição geográfica no Brasil: Centro-Oeste, Norte, Sudeste e Sul.

Difere da variedade típica da espécie por apresentar espinhos convergentes mais longos no polo posterior.

Trachelomonas bacillifera Playf. var. minima Playf., Proc. Linn. Soc. New South Wales., 40:22. pl. 03.fig. 15-16. 1915.

Figura 30

Lórica elíptica, 22-24 $\mu \mathrm{m}$ compr., 19-21 $\mu \mathrm{m}$ larg., $\mathrm{Rc} / 1=1,1$; polo anterior sem colarinho, com espessamento anelar que se projeta para dentro, coberta por espinhos bacilares obtusos semelhantes a papilas, regularmente espaçadas, com pontuações densas em depressão entre os espinhos, parede da lórica acastanhada.

Material examinado: BRASIL. Mato Grosso do Sul: Pantanal da Nhecolândia, fazenda Cáceres, 2-II-2011, D.C.L. Kufner (BHCB154607).

Distribuição geográfica no Brasil: Centro-Oeste, Norte e Sul.

Difere da variedade típica da espécie pelas menores dimensões celulares.

Trachelomonas dastuguei Balech, An. Mus. Arg. Cs. Nat. Bernardino Rivadavia, 41:293. fig. 131, 230. 1944.

Figura 31

Lórica fusiforme, 63-67 $\mu \mathrm{m}$ compr., 18-19 $\mu \mathrm{m}$ larg., $\mathrm{Rc} / 1=3,5$; polo anterior com colarinho cilíndrico sempre longo, ca. $7 \mu \mathrm{m}$ compr.; polo posterior maior, continuando com processo caudal longo, ca. 10,5 $\mu \mathrm{m}$ compr., subcônico, cuja extremidade distal é provida de espinhos retos, cônicos, finos e incolores; parede da lórica espessa, castanho-claro, pontuada, com espinhos agudos, 3-7 $\mu \mathrm{m}$ compr.; numerosos cloroplastos discoides.

Material examinado: BRASIL. Mato Grosso do Sul: Pantanal da Nhecolândia, fazenda Cáceres, 2-II-2011, D.C.L. Kufner (BHCB154607).

Distribuição geográfica no Brasil: Centro-Oeste, Norte e Sul.

Trachelomonas globularis (Awer.) Lemm. var. gigas Drezepolski, Rozpr. I Wiad. Muz. Dzieduszyckich 7/8: 5, 15, pl. I: fig. 26. 1923.

Figura 32 


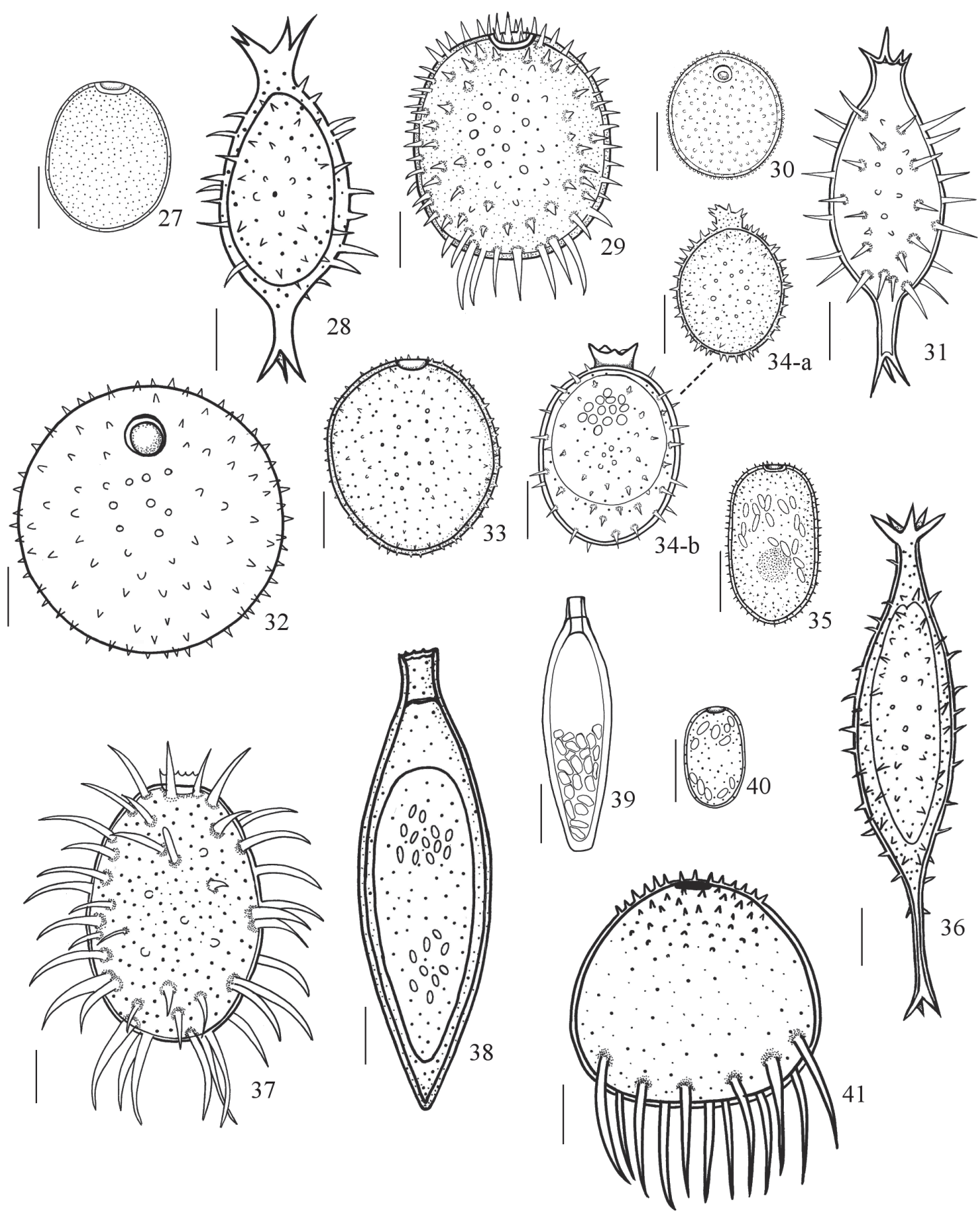

Figuras 27-41. Euglenophyta de lagoas da região da Nhecolândia, Pantanal Sul-Matogrossense, Brasil. 27. Trachelomonas abrupta var. obesa. 28. Trachelomonas acanthophora var. acanthophora. 29. Trachelomonas armata. var. steinii. 30. Trachelomonas bacillifera var. minima. 31. Trachelomonas dastuguei. 32. Trachelomonas globularis var. gigas. 33. Trachelomonas hispida var. acuminata. 34a-b. Trachelomonas hispida var. crenulatocollis. 35. Trachelomonas lemmermannii var. acuminata. 36. Trachelomonas magdaleniana. 37. Trachelomonas megalacantha var. crenulatocollis. 38. Trachelomonas molesta. 39. Trachelomonas naviculiformis. 40. Trachelomonas pulcherrima var. minor. 41 . Trachelomonas pyramidata. Escala $=10 \mu \mathrm{m}$.

Figures 27-41. Euglenophyta from lakes of Nhecolândia region, Southern Pantanal, Brazil. 27. Trachelomonas abrupta var. obesa. 28. Trachelomonas acanthophora var. acanthophora. 29. Trachelomonas armata. var. steinii. 30. Trachelomonas bacillifera var. minima. 31 . Trachelomonas dastuguei. 32. Trachelomonas globularis var. gigas. 33. Trachelomonas hispida var. acuminata. 34a-b. Trachelomonas hispida var. crenulatocollis. 35. Trachelomonas lemmermannii var. acuminata. 36. Trachelomonas magdaleniana. 37. Trachelomonas megalacantha var. crenulatocollis. 38. Trachelomonas molesta. 39. Trachelomonas naviculiformis. 40. Trachelomonas pulcherrima var. minor. 41. Trachelomonas pyramidata. Scale $=10 \mu \mathrm{m}$. 
Lórica esférica, 45-46 $\mu \mathrm{m}$ diâm.; polo anterior com espessamento anelar; parede da lórica amarelada a marrom, provida de espinhos curtos, ca. $1 \mu \mathrm{m}$ compr., pouco numerosos, dispostos irregularmente.

Material examinado: BRASIL. Mato Grosso do SuL: Pantanal da Nhecolândia, fazenda Cáceres, 2-II-2011, D.C.L. Kufner (BHCB154607).

Primeiro registro para o Brasil.

Trachelomonas hispida (Perty) Stein emend. Defl. var. acuminata Defl., Rev. Gén. Bot., 38:651.fig. 214, 215, 222. 1926.

Figura 33

Lórica elíptica ou obovada, 31-33 $\mu \mathrm{m}$ compr., ca. $32 \mu \mathrm{m}$ larg., Rc/l = 1; levemente acuminada em direção ao polo posterior; parede da lórica coberta por espinhos curtos e cônicos.

Material examinado: BRASIL. Mato Grosso do SuL: Pantanal da Nhecolândia, fazenda Cáceres, 2-II-2011, D.C.L. Kufner (BHCB154607).

Distribuição geográfica no Brasil: Norte e Sul.

Trachelomonas hispida (Perty) Stein emend. Defl. var.crenulatocollis(Maskell)Lemm.,Kryptogamenfl. Bradenburg. 3:526. 1910.

Figuras $34 \mathrm{a}-\mathrm{b}$

Lórica elíptica, 26-32 $\mu \mathrm{m}$ compr., 20-23 $\mu \mathrm{m}$ larg., $\mathrm{Rc} / 1=1,3-1,4$; polo anterior com colarinho cilíndrico, reto, crenulado na borda, ca. 3,5 $\mu \mathrm{m}$ alt., 4-5 $\mu \mathrm{m}$ compr; parede da lórica pontuada, coberta de espinhos cônicos, curtos, irregularmente espaçados; cloroplastos discoides, $1,5-2,5 \mu \mathrm{m}$ diâm.

Material examinado: BRASIL. MAto Grosso do SuL: Pantanal da Nhecolândia, fazenda Santa Filomena, 2-II-2011, D.C.L. Kufner (BHCB154606).

Distribuição geográfica no Brasil: Centro-Oeste, Norte, Sudeste e Sul.

Trachelomonas lemmermannii Wol emend. Defl. var. acuminata Defl., Nemours, p. 95, pl. 7.fig. 404, 407-409. 1926.

Figura 35

Lórica cilíndrico-cônica, 27-29 $\mu \mathrm{m}$ compr., 13-15 $\mu \mathrm{m}$ larg., $\mathrm{Rc} / 1=2-2,2$; parede pontuada provida de espinhos curtos, cônicos; polo anterior com espessamento anelar, posterior cônico.

Material examinado: BRASIL. Mato Grosso do Sul: Pantanal da Nhecolândia, fazenda Alegria, 2-II-2011, D.C.L. Kufner (BHCB154608).
Distribuição geográfica no Brasil: Centro-Oeste, Sudeste e Sul.

Trachelomonas magdaleniana Defl., Rev. Gén. Bot. 3:223. fig. 75. 1927.

Figura 36

Lórica fusiforme, 97-108 $\mu \mathrm{m}$ compr., 17-26 $\mu \mathrm{m}$ larg., $\mathrm{Rc} / 1=4,1-5,7$; lados ligeiramente arqueados, polo anterior com colarinho reto de borda espessa, provida de 4-5 espinhos grossos e divergentes; parede da lórica amarelada coberta por espinhos curtos; polo posterior estreita-se em processo caudal longo e forte, ca. $22 \mu \mathrm{m}$ compr., adornado na extremidade com 3-4 espinhos cônicos divergentes.

Material examinado: BRASIL. Mato Grosso do Sul: Pantanal da Nhecolândia, fazenda Cáceres, 2-II-2011, D.C.L. Kufner (BHCB154607).

Distribuição geográfica no Brasil: Centro-Oeste, Nordeste, Norte e Sul.

Trachelomonas megalacantha Cunha var. crenulatocollis Bourr. \& Manguin, Soc. d'Edition d'Enseignement sup. 184. P1. 23. fig. 322-323. 1952.

Figura 37

Lórica elíptica alargada, 50-57 $\mu \mathrm{m}$ compr., 33-40 $\mu \mathrm{m}$ larg., $\mathrm{Rc} / \mathrm{l}=1,5$; polo anterior com colarinho formado pela fusão de espinhos cônicos ca. $4 \mu \mathrm{m}$ compr., ca. $8 \mu \mathrm{m}$ larg.; parede da lórica pontuada, acastanhada; espinhos cônicos, distribuição irregular, retos ou levemente curvos, em direção ao polo posterior, até $20 \mu \mathrm{m}$ compr.

Material examinado: BRASIL. MATo GRosso do SuL: Pantanal da Nhecolândia, fazendas Iguaçuzinho, 2-II-2011, D.C.L. Kufner (BHCB154605), Santa Filomena, 2-II-2011, D.C.L. Kufner (BHCB154606) e Cáceres, 2-II-2011, D.C.L. Kufner (BHCB154607).

Distribuição geográfica no Brasil: Norte, Sudeste e Sul.

Trachelomonas molesta Defl., Revue Algologique 3 (1-2): 223, fig. 74. 1928.

Figura 38

Lórica elíptica, 70-73 $\mu \mathrm{m}$ compr., 17-21 $\mu \mathrm{m}$ larg., $\mathrm{Rc} / 1=3,4-4,1$, estreitando-se em direção aos polos; polo anterior com colarinho, cilíndrico, levemente alargado, provido de 5 ou 6 espinhos muito curtos; polo posterior estreitando-se levemente em processo caudal curto, ca. $6 \mu \mathrm{m}$ compr.; parede da lórica 
acastanhada, densamente coberta por pontuações; cloroplastos numerosos, elípticos, ca. $2 \mu \mathrm{m}$ compr.

Material examinado: BRASIL. Mato Grosso do SuL: Pantanal da Nhecolândia, fazenda Cáceres, 2-II-2011, D.C.L. Kufner (BHCB154607).

Distribuição geográfica no Brasil: Centro-Oeste e Sul.

Trachelomonas naviculiformis Defl., Rev. Gén. Bot. 3:222. fig. 79-80. 1927.

Figura 39

Lórica fusiforme, 52-60 $\mu \mathrm{m}$ compr., 12-14 $\mu \mathrm{m}$ larg., $\mathrm{Rc} / 1=4,3$; polo anterior terminado em colarinho com espessamento na base, cilíndrico, estreito e alto, ca. $6 \mu \mathrm{m}$ alt., e ca. $4 \mu \mathrm{m}$ larg.; polo posterior subcilíndrico terminando arredondado; lórica levemente arqueada nas laterais e atenuada para os polos; parede da lórica lisa, amarronzada; cloroplastos discoides a elípticos, ca. 1,5 $\mu \mathrm{m}$ larg., ca. 3,5 $\mu \mathrm{m}$ compr.

Material examinado: BRASIL. Mato Grosso do Sul: Pantanal da Nhecolândia, fazenda Iguaçuzinho, 2-II-2011, D.C.L. Kufner (BHCB154605).

Distribuição geográfica no Brasil: Centro-Oeste e Sul.

Trachelomonas pulcherrima Playf. var. minor Playf.,

Proc. Linn. Soc. N.S.N. 40:14, pl, I fig. 37-38. 1915 Figura 40

Lórica elíptica, 14,0-15,5 $\mu \mathrm{m}$ compr., 6,5-7,5 $\mu \mathrm{m}$ larg., $\mathrm{Rc} / 1=2-2,1$; laterais diferentemente arqueadas; polos arredondados, polo anterior com colarinho baixo; parede da lórica lisa, acastanhada; numerosos cloroplastos.

Material examinado: BRASIL. Mato Grosso do Sul: Pantanal da Nhecolândia, fazenda Alegria, 2-II-2011, D.C.L. Kufner (BHCB154608).

Distribuição geográfica no Brasil: Norte, Sudeste e Sul.

Difere da variedade típica pelas menores dimensões.

Trachelomonas pyramidata Couté et Thérézien, Rev. Hydrobiol. Trop. 18(2): 115, pl. VI, fig. 7,8. 1985. Figura 41

Lórica trapezoidal,35,5-38,0 $\mu \mathrm{m}$ compr., 33-36 $\mu \mathrm{m}$ larg., $\mathrm{Rc} / 1=1,05$; polo anterior ornamentado com espinhos curtos; polo posterior provido de espinhos fortes e longos, ca. $20 \mu \mathrm{m}$ compr.
Material examinado: BRASIL. Mato Grosso do Sul: Pantanal da Nhecolândia, fazenda Cáceres, 2-II-2011, D.C.L. Kufner (BHCB154607).

Distribuição geográfica no Brasil: Norte.

Segunda citação para o Brasil.

Trachelomonas rugulosa Stein emend. Defl., Nemours, p. 62, fig. 81-83,85,89. 1926.

Figura 42

Lórica esférica, ca. $28 \mu \mathrm{m}$ diâm., com estrias muito variáveis, geralmente oblíquas, anastomosadas, interrompidas, mais ou menos proeminentes, terminando geralmente ao redor do poro, o qual é pequeno e rodeado de um espessamento anelar forte; parede da lórica de espessura variável e de coloração amarronzada.

Material examinado: BRASIL. Mato Grosso do Sul: Pantanal da Nhecolândia, fazenda Cáceres, 2-II-2011, D.C.L. Kufner (BHCB154607).

Distribuição geográfica no Brasil: Nativa.

Trachelomonas scabra var. intermedia S. Yacubson in S. Yacubson \& C. R. Bravo, Bol. Centro Invest. Biol. 15:33, pl. I: fig. 15; pl. IV: fig. 46. 1983.

Figura 43

Lórica elíptica, 38-40 $\mu \mathrm{m}$ compr., 19-22 $\mu \mathrm{m}$ larg., $\mathrm{Rc} / 1=1,8-2$; colarinho alto, cilíndrico, ca. $8 \mu \mathrm{m}$ alt, ca. $6 \mu \mathrm{m}$ larg.; bordo liso, com abertura apical ampla; processo caudal curto e arredondado, ca. $3 \mu \mathrm{m}$ diâm.; parede da lórica espessa, marrom, coberta por numerosas partículas exógenas; cloroplastos discoides, pirenoides presentes.

Material examinado: BRASIL. Mato Grosso do Sul: Pantanal da Nhecolândia, fazenda Cáceres, 2-II-2011, D.C.L. Kufner (BHCB154607).

Distribuição geográfica no Brasil: Norte e Sul.

Trachelomonas sculpta Bal., An. Mus. Argent. Cienc. Nat., 41:245. fig. 32, 167. 1944.

Figura 44

Lórica esférica, ca. $28 \mu \mathrm{m}$ diâm.; poro circundado por anel espesso; parede da lórica provida de depressões isodiamétricas poligonais, irregulares muito próximas; parede da lórica de coloração acastanhada.

Material examinado: BRASIL. Mato Grosso do Sul: Pantanal da Nhecolândia, fazenda Cáceres, 2-II-2011, D.C.L. Kufner (BHCB154607). 
Distribuição geográfica no Brasil: Centro-Oeste, Nordeste, Norte, Sudeste e Sul.

Trachelomonas similis Stokes var. spinosa Hub.Pest., Phytoplank. Süsswasser, v. 16, n. 4, p. 342, pl. 73, fig. 722a, 1955.

Figura 45

Lórica elíptica, 25-28 $\mu \mathrm{m}$ compr., 18-21 $\mu \mathrm{m}$ larg., $\mathrm{Rc} / 1=1,3$; polo posterior e o anterior com colarinho curvo de borda irregularmente denteada; parede da lórica amarelada, irregularmente pontuada em depressão, coberta por espinhos cônicos, curtos, ca. $1 \mu \mathrm{m}$ compr.

Material examinado: BRASIL. MAto Grosso do SuL: Pantanal da Nhecolândia, fazenda Cáceres, 2-II-2011, D.C.L. Kufner (BHCB154607).

Distribuição geográfica no Brasil: Centro-Oeste, Norte, Sudeste e Sul.

Trachelomonas similis Stokes var. similis, Proc. Am.

Phil. Soc., 28:76. fig. 12. 1890.

Figura 46

Lórica elíptica, às vezes um pouco ovada, 25,0-27,5 $\mu \mathrm{m}$ compr., 18,5-19,5 $\mu \mathrm{m}$ larg., Rc/1 = 1,3; polo anterior provido de colarinho sempre encurvado com bordo irregularmente denteado; parede da lórica regularmente pontuada, de coloração acastanhada.

Material examinado: BRASIL. Mato Grosso do Sul: Pantanal da Nhecolândia, fazendas Iguaçuzinho, 2-II-2011, D.C.L. Kufner (BHCB154605) e Alegria, 2-II-2011, D.C.L. Kufner (BHCB154608).

Distribuição geográfica no Brasil: Centro-Oeste, Norte, Sudeste e Sul.

Trachelomonas superba Swir. var. superba, Archiv für Hydrobiologie und Planktonkunde 9:642, pl. 20: figs 1, 2. 1914.

Figura 47

Lórica elíptica, 27,0-29,5 $\mu \mathrm{m}$ compr., 21-24 $\mu \mathrm{m}$ larg., $\mathrm{Rc} / 1=1,2$; polo com espessamento anelar, sem colarinho; espinhos cônicos de comprimento variável, distribuídos uniformemente; parede da lórica amarela escuro a acastanhada.

Material examinado: BRASIL. Mato Grosso do Sul: Pantanal da Nhecolândia, fazendas Santa Filomena, 2-II-2011, D.C.L. Kufner (BHCB154606) e Cáceres, 2-II-2011, D.C.L. Kufner (BHCB154607).

Distribuição geográfica no Brasil: Norte e Sul.
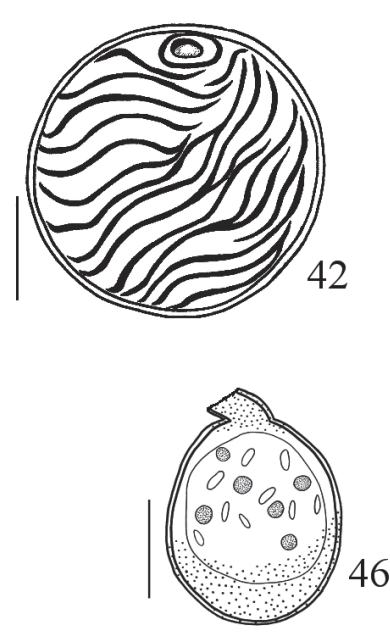
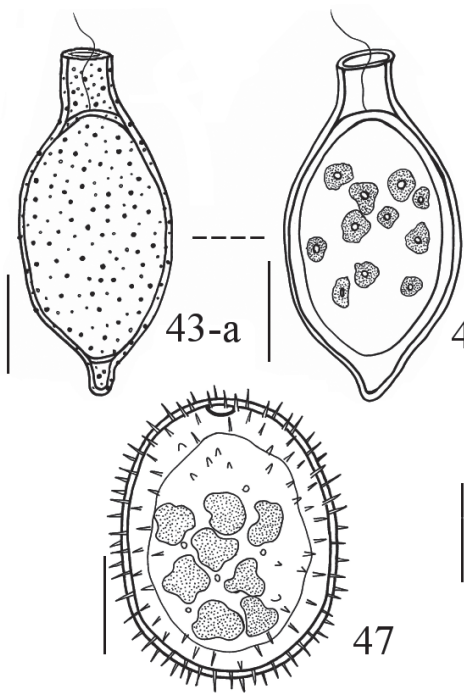

47
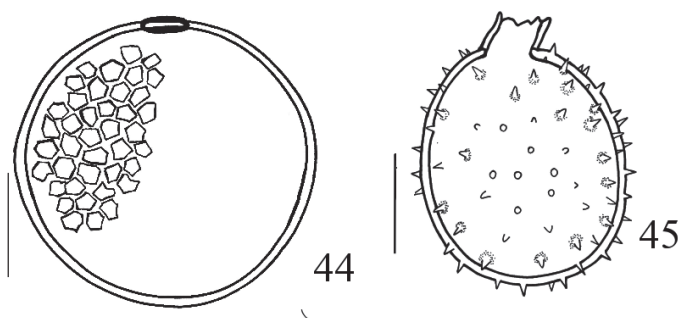

$43-b$
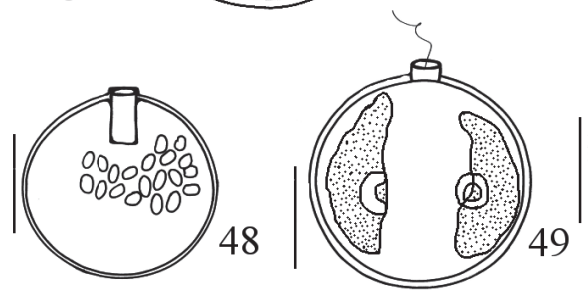

48

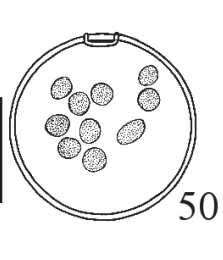

Figuras 42-50. Euglenophyta de lagoas da região da Nhecolândia, Pantanal Sul-Matogrossense, Brasil. 42. Trachelomonas rugulosa. 43. Trachelomonas scabra var. intermedia. 44. Trachelomonas sculpta. 45. Trachelomonas similis var. spinosa. 46. Trachelomonas similis. var. similis. 47. Trachelomonas superba var. superba. 48. Trachelomonas varians var. varians. 49. Trachelomonas volvocina var. derephora. 50. Trachelomonas volvocinopsis var. volvocinopsis. Escala $=10 \mu \mathrm{m}$.

Figures 42-50. Euglenophyta from lakes of Nhecolândia region, Southern Pantanal, Brazil. 42. Trachelomonas rugulosa. 43. Trachelomonas scabra var. intermedia. 44. Trachelomonas sculpta. 45. Trachelomonas similis var. spinosa. 46. Trachelomonas similis. var. similis. 47. Trachelomonas superba var. superba. 48. Trachelomonas varians var. varians. 49. Trachelomonas volvocina var. derephora. 50. Trachelomonas volvocinopsis var. volvocinopsis. Scale $=10 \mu \mathrm{m}$. 
Trachelomonas varians Defl. var. varians, Revue gén. Bot., 38:525. fig. 37-40, 42-44, 47-50. 1926.

Figura 48

Lórica globosa e/ou largamente elíptica, $18-19 \mu \mathrm{m}$ compr., 14,5-15,0 $\mu \mathrm{m}$ larg., $\mathrm{Rc} / 1=1,2$; nunca perfeitamente esférica; polo anterior com tubo interno cilíndrico, curto, 4-8 $\mu \mathrm{m}$ compr., oblíquo ou não; parede da lórica castanho-avermelhada; cloroplastos numerosos, elípticos.

Material examinado: BRASIL. Mato Grosso do Sul: Pantanal da Nhecolândia, fazenda Cáceres, 2-II-2011, D.C.L. Kufner (BHCB154607).

Distribuição geográfica no Brasil: Centro-Oeste e Sul.

Trachelomonas volvocina Ehr. var. derephora W. Conrad, Rev. Zool. Afric., 59:171. 1927.

Figura 49

Lórica esférica, 22-24 $\mu \mathrm{m}$ compr., 20-21 $\mu \mathrm{m}$ larg., $\mathrm{Rc} / 1=1,1$; ligeiramente pontuada; polo anterior com espessamento anelar e colarinho baixo, levemente cônico, ca. $3 \mu \mathrm{m}$ alt., ca. 3,5 $\mu \mathrm{m}$ larg.; parede da lórica de coloração acastanhada; dois cloroplastos com duplopirenoides; flagelo ca. 1/3 do comprimento da lórica.

Material examinado: BRASIL. MAto Grosso do Sul: Pantanal da Nhecolândia, fazenda Cáceres, 2-II-2011, D.C.L. Kufner (BHCB154607).

Distribuição geográfica no Brasil: Centro-Oeste, Nordeste, Norte, Sudeste e Sul.

Difere da variedade típica por possuir um colarinho proeminente.

Trachelomonas volvocinopsis Swir. var. volvocinopsis, Arch. Hydrobiol. Planktonic., 9:633. pl. 19. Figura 1-3. 1914.

Figura 50

Lórica esférica, 16-18 $\mu \mathrm{m}$ diâm.; poro pequeno envolto por um colar baixo, 2,5-3 $\mu \mathrm{m}$ larg., ca. $3 \mu \mathrm{m}$ alt.; parede da lórica lisa e de coloração acastanhada; cloroplastos discoides abundantes, ca. $3 \mu \mathrm{m}$ diâm.

Material examinado: BRASIL. Mato Grosso do Sul: Pantanal da Nhecolândia, fazendas Iguaçuzinho, 2-II-2011, D.C.L. Kufner (BHCB154606), Cáceres, 2-II-2011, D.C.L. Kufner (BHCB154607) e Alegria, 2-II-2011, D.C.L. Kufner (BHCB154608).

Distribuição geográfica no Brasil: Centro-Oeste, Nordeste, Norte, Sudeste e Sul.
As lagoas amostradas apresentaram profundidades que variaram de 50 a $100 \mathrm{~cm}$ e transparência da água de 28 a $58 \mathrm{~cm}$. O pH variou de ácido a levemente alcalino $(4,8$ a 7,8$)$. As lagoas também apresentaram as seguintes características para as variáveis abióticas: a condutividade elétrica variou entre $22-276,9 \mu \mathrm{S} \mathrm{cm}^{-1}$ e a matéria orgânica de 10 a $32,5 \mathrm{mg} \mathrm{L}^{-1}$, temperatura da água em torno de $29^{\circ} \mathrm{C}$, além de cobertura intensa de macrófitas aquáticas dos gêneros Pontederia, Eichhornia e Salvinia. A maior ocorrência de Euglenophyta foi registrada na lagoa da fazenda Cáceres, cujo pH foi de 6,14 e cujos níveis de oxigênio dissolvido $\left(0,2 \mathrm{mg} \mathrm{L}^{-1}\right)$ foi o mais baixo registrado nesse trabalho.

Estudos realizados por Alves-da-Silva \& Bridi (2004a), Alves-da-Silva \& Bicudo (2009), corroborando os achados de Weik (1967), mostraram que espécies do gênero Phacus têm preferência por águas com características similares às observadas neste estudo, como águas quentes $\left(27{ }^{\circ} \mathrm{C}\right), \mathrm{pH}$ de levemente ácido $(6,19)$ e ricas em matéria orgânica (11 mg L-1). Conforti (1993b) e Zaburlín et al. (2004) também descreveram ambientes com $\mathrm{pH}$ ácido, baixo teor de oxigênio dissolvido e presença de macrófitas, respectivamente para os gêneros Trachelomonas e Strombomonas.

Amaior ocorrência de táxons foi observada na lagoa Cáceres, com condutividade elétrica elevada e maiores quantidades de matéria orgânica em comparação com as demais. O gênero Strombomonas parece estar bem adaptado às variações nas concentrações de íons na coluna d'água (Conforti 1993a; Zaburlin et al. 2004; Alves-da-Silva \& Kurrle 2009), porém neste trabalho o gênero somente foi encontrado na lagoa cujos valores de condutividade elétrica foram maiores $\left(276,9 \mu \mathrm{S} \mathrm{cm}^{-1}\right)$.

Do total dos táxons identificados, Trachelomonas globularis var. gigas, foi registrada pela primeira vez no Brasil. Outras duas espécies foram citadas pela segunda vez no país, Lepocinclis americana e Trachelomonas pyramidata, sendo o primeiro registro feito por Conforti (1993b, 1994, respectivamente) para o lago Camaleão, no Estado do Amazonas. É possível que as poucas citações para este grupo sejam devidas ao restrito número de trabalhos taxonômicos desenvolvidos até o momento na área de estudo.

Euglena caudata var. caudata, Lepocinclis acus, Strombomonas fluviatilis var. levis, Trachelomonas armata var. steinii, T. megalacantha var. crenulatocollis, $T$. superba var. superba e $T$. 
volvocinopsis var. volvocinopsis foram os táxons com maior ocorrência e maior número de indivíduos por amostra. Em contrapartida, as espécies com ocorrência restrita em apenas um dos ambientes amostrados e/ou que apresentaram baixa ocorrência por amostra foram E. splendens, T. bacillifera var. minima, T. hispida var. acuminata, T. pyramidata, T. rugulosa. T. sculpta e T. varians.

Os novos registros de Euglenophyta tanto para o Brasil quanto para a região Pantaneira demonstram que novos estudos taxonômicos devem ser estimulados para a planície, especialmente considerando-se a ênfase que estudos sobre biodiversidade têm tido nos últimos anos (Striebel et al. 2009) e, ao mesmo tempo, as ameaças e as alterações que o Pantanal vem sofrendo com o desenvolvimento econômico da região (Harris et al. 2005).

\section{Agradecimentos}

À FAPEMIG, pela bolsa de doutorado concedida à Deborah Christiane Leite Kufner. Ao CNPQ, pelo financiamento da pesquisa à Alessandra Giani. À equipe da Embrapa Pantanal, especialmente nas pessoas de Marcia D. Oliveira e Josias C. Oliveira, pela logística e apoio nas coletas. Ao professor Cleber C. Figueredo, da UFMG, pelo auxílio nas identificações.

\section{Literatura citada}

Abdon, M.M., Silva, J.S.V., Pott, V.J., Pott, A. \& Silva, M.P. 1998. Utilização de dados analógicos do Landsat-TM na discriminação da vegetação de parte da sub-região da Nhecolândia no Pantanal. Pesquisa Agropecuária Brasileira 33 (número especial), pp. 1799-1813.

Allem, A.C. \& Valls, J.F.M. 1987. Recursos forrageiros nativos do Pantanal Mato-Grossense. Documentos, 8, Embrapa/Cenargen, Brasília.

Alves-da-Silva, S.M. \& Bicudo, C.E.M. 2009. Cryptoglena, Monomorphina and Phacus (Euglenophyceae) of a reservoir in the State of Rio Grande do Sul, southern Brazil. Revista Brasileira de Botanica 32: 253-270.

Alves-da-Silva, S.M. \& Bridi, F.C. 2004a. Estudo de Euglenophyta no Parque Estadual Delta do Jacuí, Rio Grande do Sul, Brasil. 2. Os gêneros Phacus Dujardin e Hyalophacus (Pringshein) Pochmann. Iheringia 59: 75-96.

Alves-da-Silva, S.M. \& Bridi, F.C. 2004b. Euglenophyta no parque Estadual Delta do Jacuí, Rio Grande do Sul, Sul do Brasil. 3. Gênero Strombomonas Defl. Acta Botanica Brasilica 18: 555-572.
Alves-da-Silva, S.M. \& Fortuna, J.R. 2006. Euglenophyceae de ambientes lênticos na planície costeira do Rio Grande do Sul, sul do Brasil: gêneros Euglena Ehr. Lepocinclis Perty. Acta Botanica Brasilica 20: 411-422.

Alves-da-Silva, S.M. \& Fortuna J.R. 2008. O gênero Phacus (Euglenophyceae) em sistemas lênticos da Planície Costeira do Rio Grande do Sul, sul do Brasil. Acta Botanica Brasilica 22: 684-700.

Alves-da-Silva, S.M. \& Hahn, A.T. 2001. Lista de Euglenophyta registradas em ambientes de águas continentais e costeiras do Estado do Rio Grande do Sul, Brasil. Iheringia 55: 171-188.

Alves-da-Silva, S.M. \& Hahn, A.T. 2004. Study of Euglenophyta in the Jucuí Delta State Park, Rio Grande do Sul, Brazil. 1. Euglena Ehr., Lepocinclis Perty. Acta Botanica Brasilica 18: 123-140.

Alves-da-Silva, S.M. \& Kurrle, I.L.P. 2009. O gênero Strombomonas (Euglenophyceae pigmentadas) em ambientes lênticos na Planície Costeira do Rio Grande do Sul, Brasil. Acta Botanica Brasilica 23: 944-955.

Alves-da-Silva, S.M. \& Tamanaha, M.S. 2008. Ocorrência de Euglenophyceae pigmentadas em rizipiscicultura na Região do Vale do Itajaí, SC, Sul do Brasil. Acta Botanica Brasilica 22: 145-163.

Alves-da-Silva, S.M. Cabreira, J.C., Consoni, K.F. \& Lobo, E.A. 2013. Gênero Strombomonas Deflandre (Euglenophyceae pigmentadas em ambiente lótico subtropical, município de Triunfo, RS, Brazil: Riqueza e distribuição geográfica. Hoehnea 40: 381-402.

APHA. 1998. Standard methods for the examination of water and wastewater. In: 19 th American Public Health Association, Washington.

Cardoso, S.J., Roland, F., Huszar, V.L.M. \& LoverdeOliveira, S.M. 2012. Phytoplankton abundance, biomass and diversity within and between Pantanal wetland habitats. Limnologica, 42: 235-241.

Conforti, V.T.D. 1993a. Study of the Euglenophyta from Camaleão lake (Amazonas-Brazil), I- Trachelomonas Ehr.Revue Hydrobiological Tropical 26: 3-18.

Conforti, V.T.D. 1993b. Study of the Euglenophyta from Camaleão lake (Manaus-Brazil). I- Trachelomonas Ehr. Revue Hydrobiologie tropicale 26: 187-197.

Conforti, V.T.D. 1994. Study of the Euglenophyta from Camaleão Lake (Manaus, Brazil). III. Euglena Ehr., Lepocinclis Perty, Phacus Duj. Revue Hidrobiologique Tropicale 27:3-21.

Conrad, W. \& Van Mell, L. 1952. Materiaux pour une monographie de Trachelomonas Ehrenberg, C., 1834, Strombomonas Deflandre, G., 1930, et Euglena Ehrenberg, C. 1832, genres d'Euglenacées. Memoires de Institut Royal des Sciences naturelle de Belgique 124: $1-176$.

Deflandre, G. 1926. Monographie du genre Trachelomonas Ehrenberg. André Lesot, Nemours. 
Domitrovic, Y.Z. 2002. Structure and variation of the Paraguay River phytoplankton in two periods of its hydrological cycle. Hydrobiologia 472: 177-196.

Espíndola, E.G., Matsumura-Tundisi, T. \& Moreno, I.D. 1996. Estrutura da comunidade fitoplanctônica da Lagoa Albuquerque (Pantanal Matogrossense), Mato Grosso do Sul, Brasil. Acta Limnologica Brasiliensia 8: 13-27.

Harris, M.B., Tomas, W.M., Mourão, G., Silva, G.J., Guimarães, E., Sonoda F. \& Facchini, E. 2005. Challenges to safeguard the Pantanal wetlands, Brazil: threats and conservation initiatives. Conservation Biology 19: 714-720.

Kosmala, S., Bereza, M., Milanowski, R., Kwiatowski, J. \& Zakry's, B. 2007. Morphological and molecular examination of relationships and epitype establishment of Phacus pleuronectes, Phacus orbicularis and Phacus hamelli. Journal of Phycology 43: 1071-1082.

Malone, C.F.S., Santos, K.R.S. \& Sant'Anna, C.L. 2012. Algas e cianobactérias de ambientes extremos do Pantanal Brasileiro. Oecologia Australis 16: 745-755.

Marin, B., Palm, A., Klingberg, M. \& Melkonian, M. 2003. Phylogeny and taxonomic revision of plastidcontaining Euglenophytes based on SSU rDNA sequence comparisons and synapomorphic signatures in the SSU rRNA secondary structure. Protist 154: 99-145.

Neiff, J.J. 1990. Ideas para la interpretación ecológica del Paraná. Interciencia 15: 424-441.

Oliveira, M.D. \& Calheiros, D.F. 2000. Flood pulse influence on phytoplankton communities of the south Pantanal floodplain, Brazil. Hydrobiologia 427: 101-112.

Palmer, C.M. 1969. A composite rating of algae tolerating organic pollution. Journal of Phycology 5: 78-82.
Pochmann, A. 1942.Synopsis der Gattung Phacus. Archiv für Protistenkunde 95: 81-252.

Round, F.E. 1983. Biologia das algas. 2 ed. Editora Guanabara Dois, Rio de Janeiro.

Salazar, C. 2004. Euglenophyta pigmentadas asociadas a Hymenachne amplexicaulis en una sabana tropical inundable. Acta Botanica Venezuelica 27: 101-125.

Santos, K.R.S \& Sant'Anna, C.L. 2010. Cianobactérias de diferentes tipos de lagoas (salina, salitrada e baía) representativas do Pantanal da Nhecolândia, MS, Brasil. Revista Brasileira de Botânica 33: 61-83.

Striebel, M., Behl, S. \& Stibor, H. 2009. The coupling of biodiversity and productivity in phytoplankton communities: Consequences for biomass stoichiometry. Ecology 90: 2025-2031.

Swirenko, D. 1915. Étude systématique et géographique des Euglénacées. Travaux de l'Institut de Botanique de l'Universite de Kjarkoffn.

Tell, G. \& Conforti V. 1986. Euglenophyta pigmentadas de la Argentina. Bibliotheca Phycologica 75 : 1-301.

Tell, G. \& Couté, A. 2008. Trachelomonas armata (Her.) Stein (Euglenophyceae) and related morphotypes from Argentina. Algological Studies 128: 21-35.

Weik, K.L. 1967. A revision of the genus Phacus Dujardin in Illinois. Tese (Doutorado) Departamento de Botânica, Illinois, USA.

Wetzel, R.G. 2001. Limnology: lake and river ecosystems. Elsevier Science, Orlando.

Zaburlín, N.M., Goñi O. \& Conforti V.T.D. 2004. Estudo taxonômico de las Strombomonas (Euglenophyta) del Arroyo Yacarey, provincia de Corrientes, Argentina. Iheringia 59: 117-130. 